\title{
VISUALIZING THE IMPACT OF HOME ADVANTAGE IN NATIONAL BASKETBALl ASSOCIATION-NBA
}

\author{
${ }^{1}$ Ekas Singh Abrol, ${ }^{2}$ Puneet Singh Lamba, ${ }^{3}$ Achin Jain \\ ${ }^{1}$ Guru Tegh Bahadur Institute of Technology, GGSIPU, New Delhi, India \\ ${ }^{2,3}$ Bharati Vidyapeeth's College of Engineering, New Delhi, India
}

\begin{abstract}
In sports, home advantage describes the benefits that the home team enjoys over the away team. These benefits are manifested due to cognitive effects that the local home crowd may have over the competitors or umpires, advantages of playing in familiar situations resulting in better adaptability, specific rules favouring the home team directly or indirectly, the away teams often suffer from jet lag due to change in time zones or from the tenacity of travel, etc. In this paper, various exploratory data visualization techniques have been utilized to observe the impact of home advantage in professional basketball association league NBA- National Basketball Association. Further the factors attributing to home advantage in sports are analysed. It was observed that when the team had performed well at home games, the results reflected the same for away games; however, home advantage was still distinctively visible.
\end{abstract}

\section{KEYWORDS}

Basketball, home advantage, data visualization .

\section{INTRODUCTION}

Home advantage is a boisterous phenomenon that manifests in all professional sports attributing to elements such as home audience involvement, travel fatigue, familiarity with playing conditions etc. In past home advantage has been well documented by Courneya and Carron (1992) and by Nevill and Holder (1999) for every American game such as basketball, rugby, ice hockey and by Pollard (2008) in the interest of football. In basketball, research correlating to game factors ensuring a win at home games have recently fixated on team performance analysis through match-cognitive statistics (Ibáñez et al., 2008; Sampaio et al., 2010; Sampaio et al., 2006). Earlier studies (Silva \& Andrew, 1987; Varca, 1980) focused on the precedence of vociferous crowd support in player behavior that increased the assertive actions of home teams. About European basketball, Pollard and Gómez (2007) inculcated and evaluated continuance of home advantage in professional leagues held in majority of the countries subsiding in the European continent. They concluded it to be greater than that of games in NBA. However, most of these studies were predicated in accordance with non-major leagues in regard to only a single country.

In basketball, data mining techniques are mostly used for purposes such as for comparing player on player battle other than the prediction of match outcomes. In this paper we implement multiple visualization techniques to monitor and infer trends regarding the existence of home advantage in NBA. Remainder of the paper is structured as follows: Section 2 describes the various factors attributing to Home Advantage in sports. Section 3, Methodology, describes data collection and exploratory data visualization techniques. Monitoring data trends and discussion of results has been carried out in Section 4. Section 5 provides a brief conclusion regarding the topic and results 


\section{Factors Attributing to Home Advantage in SPORTS}

The hypothesized attributes regarding causation of home advantage are as follows:

\subsection{Home Audience Involvement}

The vociferous local crowd support can commove spirit with strife in the home team by rewarding better gameplay and intimidating the away players, thus positively correlating as influential attributes for the home team. Home advantage, in past has been investigated from the viewpoint of a social psychologist and the results accentuated the notability of social support liable to the home audience; however, the explicit nature of local crowd support remained obsolete. Moreover, for American indoor sports the relations of fans with players are imminent, exhibited preeminent home advantage when compared with outdoor sports [2].

\subsection{Tenacity of Travel}

Over years although travel regarding sports has become easier, faster, and comfortable, however home advantage has declined very slightly and remains unchanged. It was widely attributed for the conventional held beliefs regarding home advantage to be tied with fatigue as an important factor. Long distance travels result in fatigue and often leads to an unpropitious effect on the performance of players [14].

\subsection{Familiarity with home conditions}

Multiple ways subsist in which familiarity with home conditions can avail advantage to the local team. In most cases it was observed that the dimensions regarding ground layout in outdoor sports such as cricket and baseball or playing courts of various indoor sports were organized in a way to favour the local team. A classic example in the game of ice hockey was regarding Cherry Hill Arena, situated in Philadelphia. The slanted ice surface of the court coerced the opposing team to glissade the match skyward. This trend was further observed in basketball as well. The home stadium of Boston Celtics' had a parquet floor which was said to give the Celtics an advantage over the visiting teams, as they were more liable to be habituated with the playing surface. Owing to few familiar sights and faces engenders truculent conditions which act against the visiting players. Unhygienic food and climatic conditions in intercontinental competitions may act against the away team players as well [17].

\subsection{Referee Biasing}

It has been noticed during past years that an uproarious crowd can impel the judgment by umpires or referees favouring the local team. This observation was put forth in Cricket, where umpires provided by the home country ruled out LBW decisions in the favour of home team. A possible explication was subconscious partialness by the referees, influenced by immensely colossal, partisan, and boisterous home crowd. One of the studies correlated how likely the game officials called a 'loose ball foul' on all-star players in comparison to non-star NBA players. Results were formulated over a time of three years constituting 3,500 games contributing to 1.5 million plays being examined. The results showcased 42 percent of loose ball foul situation on star players in relation to 57 percent of the foul calls on non-star players. Further results formulated to a drastic shift, favouring star players when they commit a foul with only 28 percent of fouls being accounted about them, thus a sizably voluminous drop from 42 percent in earlier case [16]. 


\subsection{Special Tactics}

The players of away team mostly imitate defensive techniques which further accounts for home team with a psychological and areal advantage [7].

\subsection{Psychological or Cognitive Factors}

Accepting the notion of subsisting home advantage is liable to affect the performance and attitude of a player. In year 2000, Bran and Widemeyer reported about player confidence correlating to game location. It was reported that $76 \%$ basketball players out of 74 players claimed their "espirit de-corps" or self-assurance to be greater whilst playing in familiar home conditions. Alongside faith in oneself, team's cumulative efficiency or assurance in the team's competence was found to be higher. It is excessively consequential that teammates have faith in amongst themselves because their interdependency amongst each other manifests a win. This further connotes the perception of home advantage to be a vital factor owing to a win $[2,8]$.

\section{Methodology}

The steps that have been carried out to visualize and monitor data trends regarding Home Advantage in NBA have been depicted in Fig. 1.

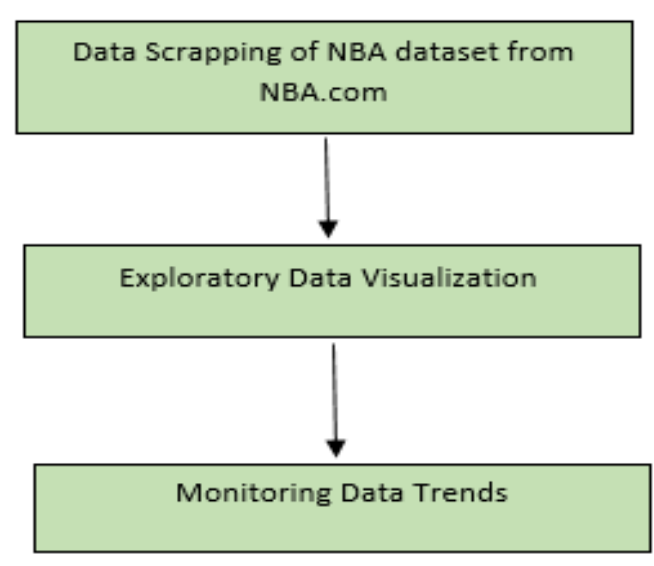

\subsection{Data Collection}

Figure 1. Methodology

The data for National Basketball Association (NBA) dataset (displayed in Fig 2.) is scrapped from NBA.com. It contains both home and away performance of 1216 teams during the last 60 years from 1950-2010. A snapshot of the dataset is displayed in Figure 2. For real time score and clock analysis, companies like Stat Inc. are directly linked to the scoreboard- so that the data comes in automatically. The percentage variables in the dataset, namely, HomePCT, AwayPCT and TotalPCT have been derived from Wins, Loss, HomeWins, HomeLoss, AwayWins and AwayLoss. HomePCT is defined as the ratio of HomeWins to sum of HomeWins and HomeLoss. AwayPCT is defined as the ratio of AwayWins to sum of AwayWins and AwayLoss. PCT refers to win percentage. 
Computer Applications: An International Journal (CAIJ), Vol.8, No.3, August 2021

\begin{tabular}{|c|c|c|c|c|c|c|c|c|c|c|c|c|c|}
\hline \multicolumn{10}{|c|}{ ه | $\mid \nabla$ Filter } & \multicolumn{4}{|c|}{ a } \\
\hline & Year & Team & $=$ & Wins & Loss & $\begin{array}{l}\text { Home } \\
\text { wins }\end{array}$ & $\begin{array}{l}\text { Home } \\
\text { Loss }\end{array}$ & $\begin{array}{l}\text { Away } \\
\text { Wins }\end{array}$ & $\begin{array}{l}\text { Away } \\
\text { Loss }\end{array}$ & HomePCT & AwayPCT & TotalPCT & \\
\hline 28 & 1995 & Hawks & & 46 & 36 & 26 & 15 & 20 & 21 & 0.6341463 & 0.48780488 & 0.5609756 & ^ \\
\hline 29 & 1996 & Hawks & & 56 & 26 & 36 & 5 & 20 & 21 & 0.8780488 & 0.48780488 & 0.6829268 & \\
\hline 30 & 1997 & Hawks & & 50 & 32 & 29 & 12 & 21 & 20 & 0.7073171 & 0.51219512 & 0.6097561 & \\
\hline 31 & 1998 & Hawks & & 31 & 19 & 16 & 9 & 15 & 10 & 0.6400000 & 0.60000000 & 0.6200000 & \\
\hline 32 & 1999 & Hawks & & 28 & 54 & 21 & 20 & 7 & 34 & 0.5121951 & 0.17073171 & 0.3414634 & \\
\hline 33 & 2000 & Hawks & & 25 & 57 & 18 & 23 & 7 & 34 & 0.4390244 & 0.17073171 & 0.3048780 & \\
\hline 34 & 2001 & Hawks & & 33 & 49 & 23 & 18 & 10 & 31 & 0.5609756 & 0.24390244 & 0.4024390 & \\
\hline 35 & 2002 & Hawks & & 35 & 47 & 26 & 15 & 9 & 32 & 0.6341463 & 0.21951219 & 0.4268293 & \\
\hline 36 & 2003 & Hawks & & 28 & 54 & 18 & 23 & 10 & 31 & 0.4390244 & 0.24390244 & 0.3414634 & \\
\hline 37 & 2004 & Hawks & & 13 & 69 & 9 & 32 & 4 & 37 & 0.2195122 & 0.09756098 & 0.1585366 & \\
\hline 38 & 2005 & Hawks & & 26 & 56 & 18 & 23 & 8 & 33 & 0.4390244 & 0.19512195 & 0.3170732 & \\
\hline 39 & 2006 & Hawks & & 30 & 52 & 18 & 23 & 12 & 29 & 0.4390244 & 0.29268293 & 0.3658537 & \\
\hline 40 & 2007 & Hawks & & 37 & 45 & 25 & 16 & 12 & 29 & 0.6097561 & 0.29268293 & 0.4512195 & \\
\hline 41 & 2008 & Hawks & & 47 & 35 & 31 & 10 & 16 & 25 & 0.7560976 & 0.39024390 & 0.5731707 & \\
\hline 42 & 2009 & Hawks & & 53 & 29 & 34 & 7 & 19 & 22 & 0.8292683 & 0.46341463 & 0.6463415 & \\
\hline 43 & 2010 & Hawks & & 44 & 38 & 24 & 17 & 20 & 21 & 0.5853659 & 0.48780488 & 0.5365854 & \\
\hline 44 & 1950 & Bullets & & 24 & 42 & 21 & 11 & 3 & 25 & 0.6562500 & 0.10714286 & 0.3636364 & \\
\hline 45 & 1951 & Bullets & & 20 & 46 & 17 & 15 & 2 & 22 & 0.5312500 & 0.08333333 & 0.3030303 & \\
\hline 46 & 1952 & Bullets & & 16 & 54 & 11 & 20 & 1 & 19 & 0.3548387 & 0.05000000 & 0.2285714 & \\
\hline 47 & 1953 & Bullets & & 16 & 56 & 12 & 20 & o & 20 & 0.3750000 & 0.00000000 & 0.2222222 & \\
\hline 48 & 1963 & Bullets & & 31 & 49 & 20 & 19 & 8 & 21 & 0.5128205 & 0.27586207 & 0.3875000 & \\
\hline 49 & 1964 & Bullets & & 37 & 43 & 23 & 14 & 12 & 19 & 0.6216216 & 0.38709677 & 0.4625000 & \\
\hline
\end{tabular}

Figure 2. NBA Dataset

\subsection{Exploratory data visualization}

Machine learning is a computer system's method based on the art of study and construction of algorithms that can learn from and make predictions on data. We visualize and monitor the dataset to infer trends regarding home advantage, using ggplot2 system for R. It is a package based upon grammar of graphics, which considers good parts of base and lattice graphics while ignoring the bad one. It provides a potent model of graphics that makes it facile to engender intricate multi-layered graphs. In this paper, we start with summary graphs to understand the overall home advantage existence and trend in NBA. Later, we drill down to team-level infographs to explore unique trends, if any. We make use of scatter plot, boxplot, and linear graphs. For scatter plot we pair up values of two continuous variables of the dataset; HomePCT and AwayPCT and display them as geometric points inside a Cartesian diagram. For linear infographs we plot summary median statistics of NBA teams for 60 years to visualize and compare the data trends of how a team performs at home and away games. Box plots are formulated to visualize and compare the home and away performance measure of teams selected at random; alongside drawing a contrast regarding performance variation at home and away games. Lastly, we plot HomePCT, AwayPCT together as trend lines to understand the variance in HomePCT and AwayPCT with respect to time for a particular team.

\section{Results}

We use the following data visualization infographs to visualize and monitor Home Advantage.

\subsection{Scatter Plot}

We use scatter plot to see the relationship between the continuous variables; HomePCT and AwayPCT as shown in fig. 3. From the figure, we infer that distinctive home advantage is visible since for most observations the HomePCT value is greater than 0.5. However, no strict inferences can be drawn since the above figure represents 60 years of data for multiple NBA teams. 


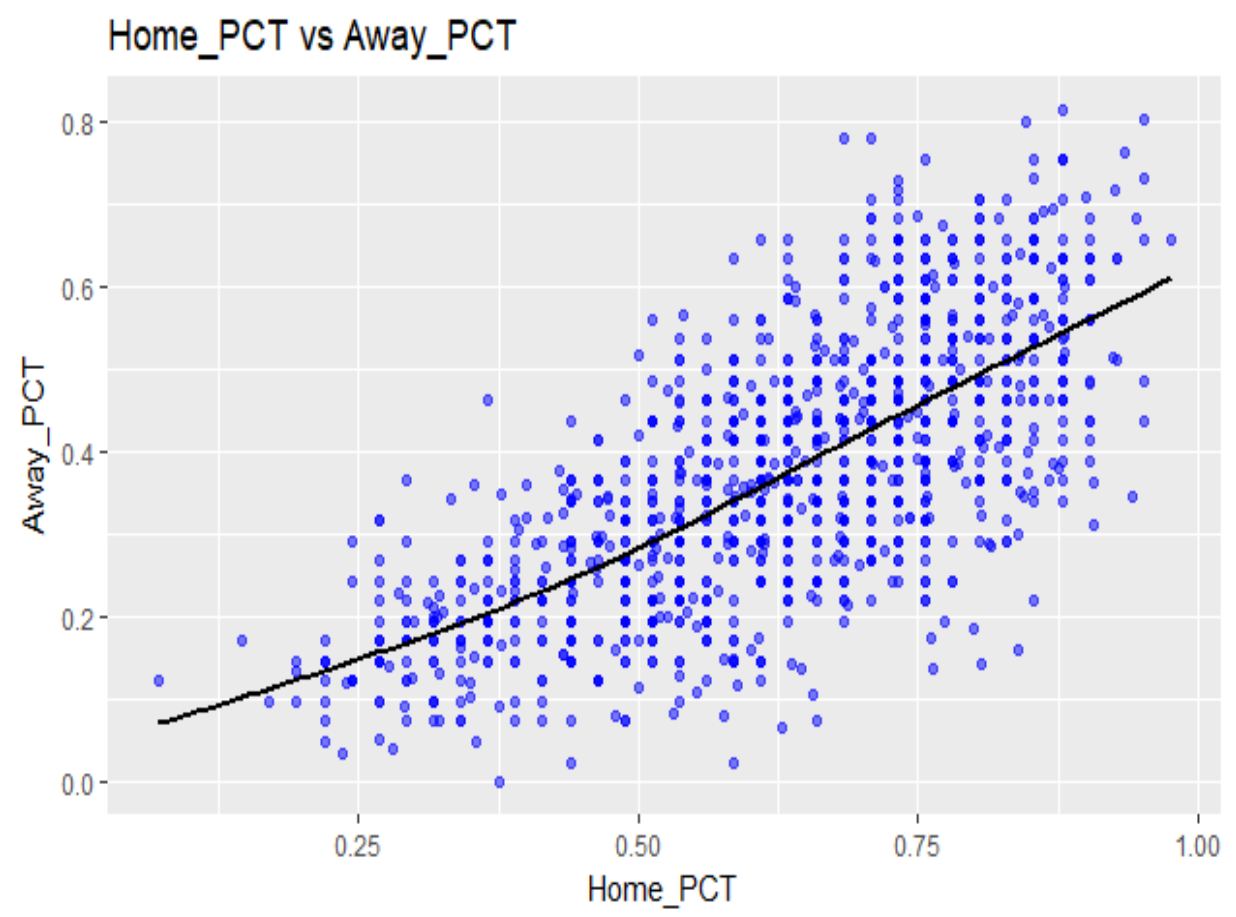

Figure 3. Home PCT V/S Away PCT

\subsection{Median Trends}

Now, we look at the trends in median HomePCT and AwayPCT from 1950 to 2010.

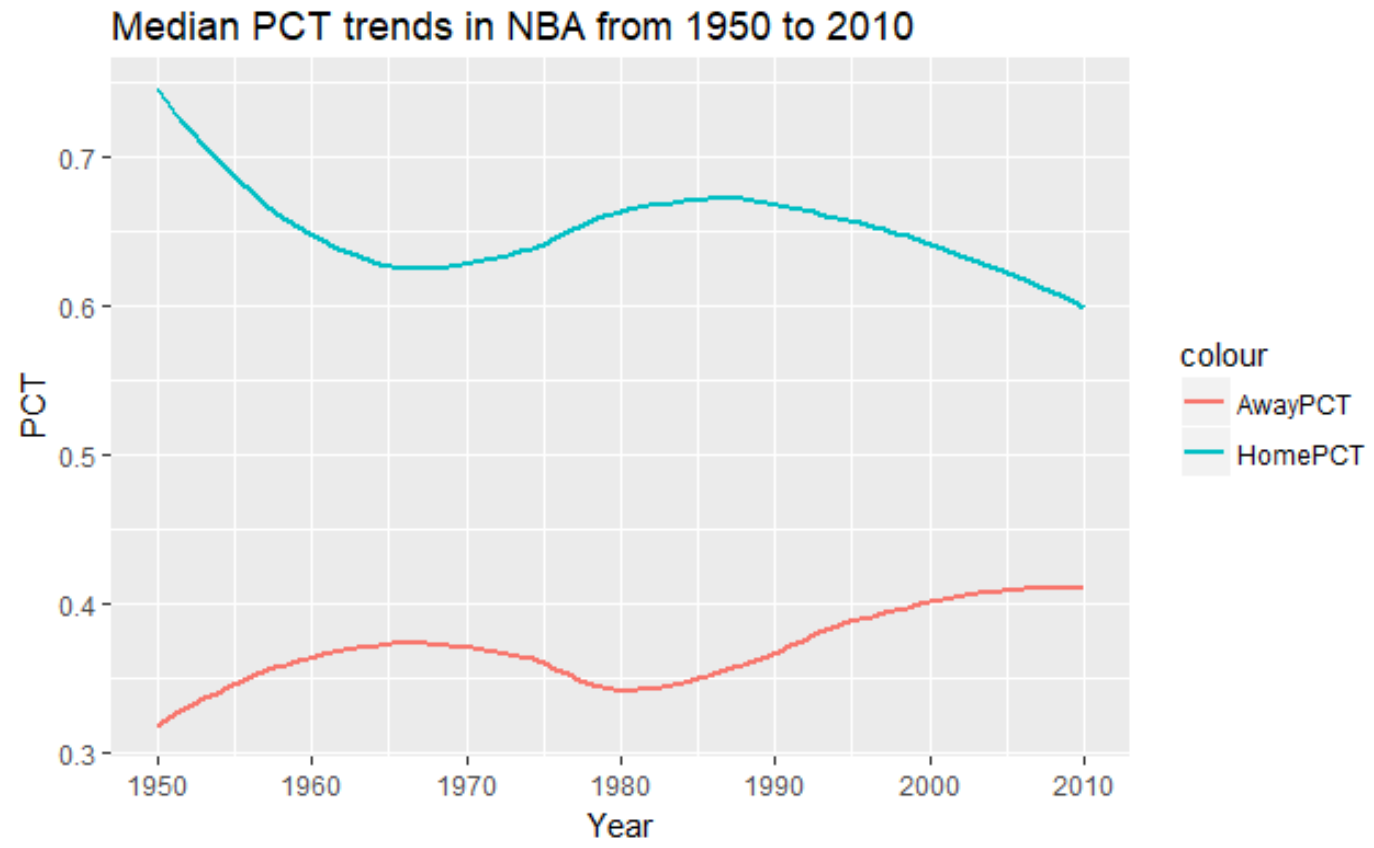

Figure 4. Median trends HomePCT \& AwayPCT

The above infograph depicted in fig.4 represents summary statistics. Since mean is sensitive to outliers, we chose median as the average statistic. We observe, the median HomePCT value is significantly larger than the Away PCT value across all years. This means that, overall, teams 
have consistently performed better at home games than at away games. Thus, this infograph depicts the existence of home advantage in NBA.

\subsection{Boxplot}

We use boxplot to observe the variation in HomePCT and AwayPCT for 15 teams, selected at a random, from 1950 to 2010 as shown in fig. 5 and 6.

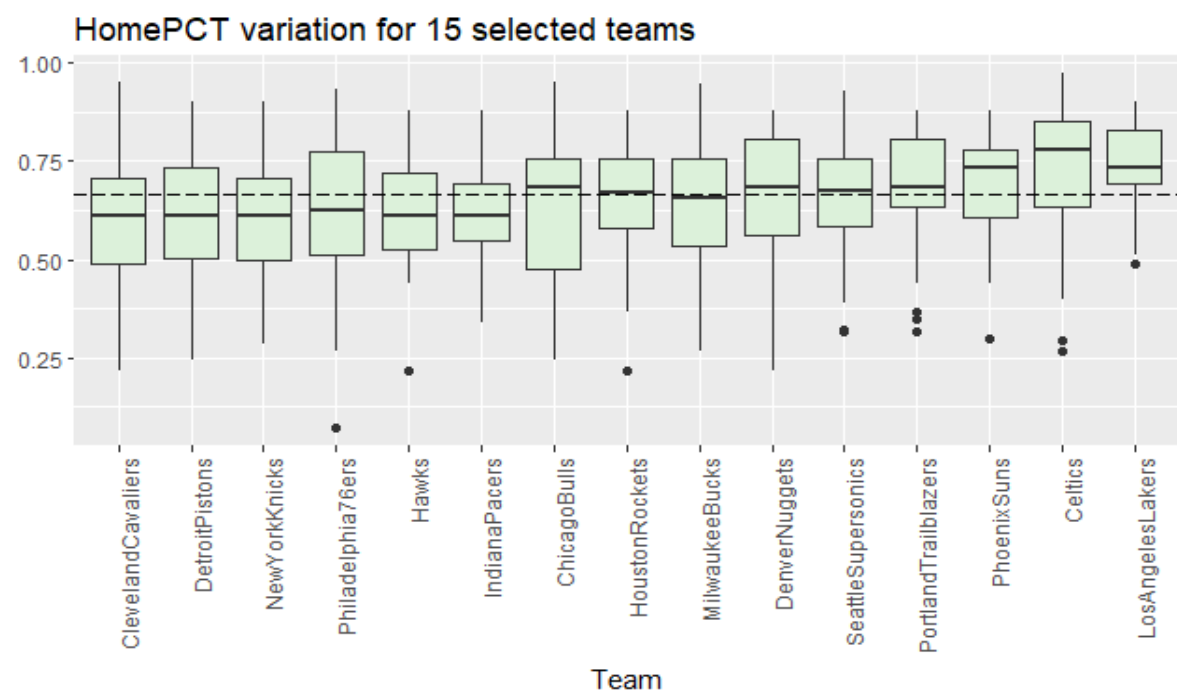

Figure 5. HomePCT Variation for 15 teams

\section{AwayPCT variation for 15 selected teams}

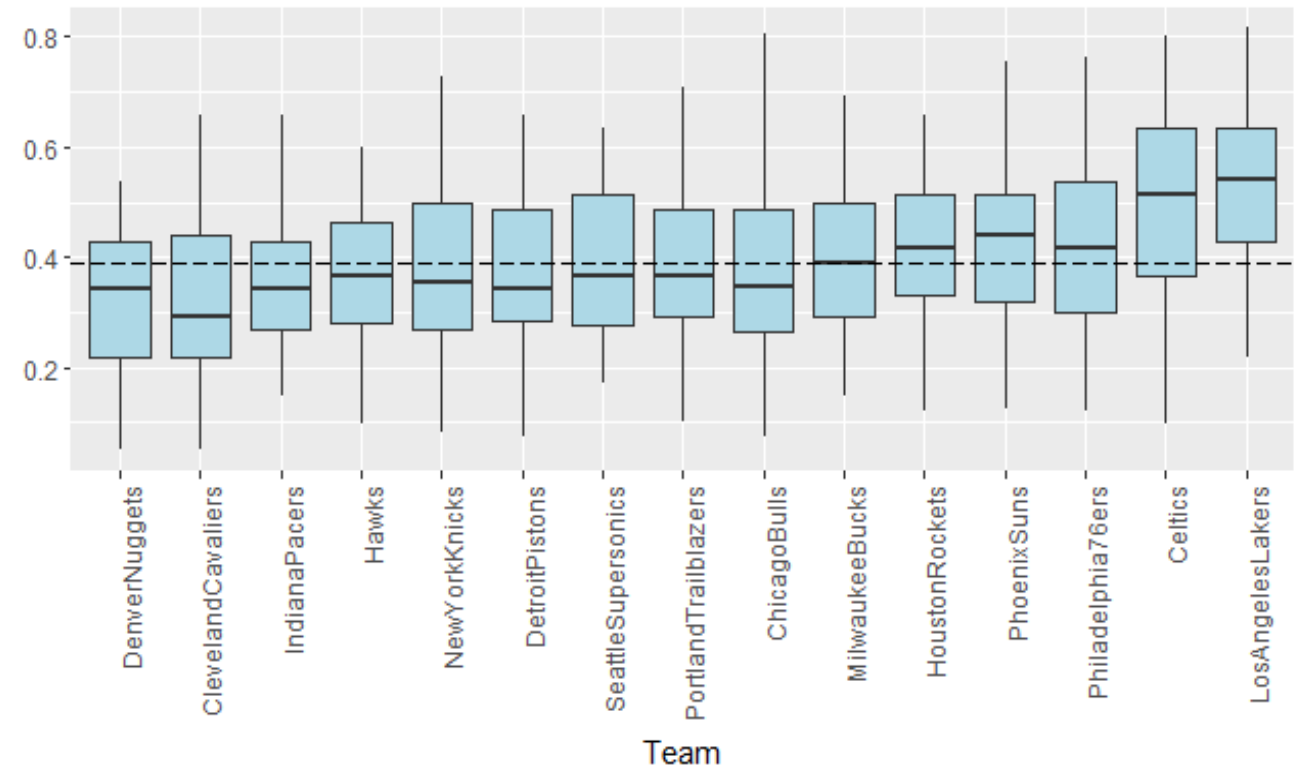

Figure 6. AwayPCT Variation for 15 teams

From the above two boxplots we infer that, across all teams that were randomly selected, HomePCT has been greater than AwayPCT. It can also be observed that for a lot of teams (example: Seattle Supersonics, Indian Pacers, Detroit Pistons, Chicago Bulls) the variation in AwayPCT has been greater than the variation in HomePCT. This brings the 'form' of the team 
into picture. The 'form' of a team in sports team refers to how well a team has performed in recent games due to regular exercises and practice games. To maintain the 'form' of a team at its peak, teams continue to conduct various training exercises and workout drills. Coaches make their star players to play to ensure the team winning the key games.

\subsection{Linear Trends}

For the following info graphs (fig. 7 and fig. 8), we plot HomePCT and AwayPCT together as trend lines to understand the variance in HomePCT and AwayPCT with respect to time for a particular team. It is concluded that the team form is important. In most teams the team has performed well at home and away at the same time. Although there is still a significant difference between the HomePCT and the AwayPCT and seldom have these two figures been close for any team, therefore proving a distinctive home advantage.
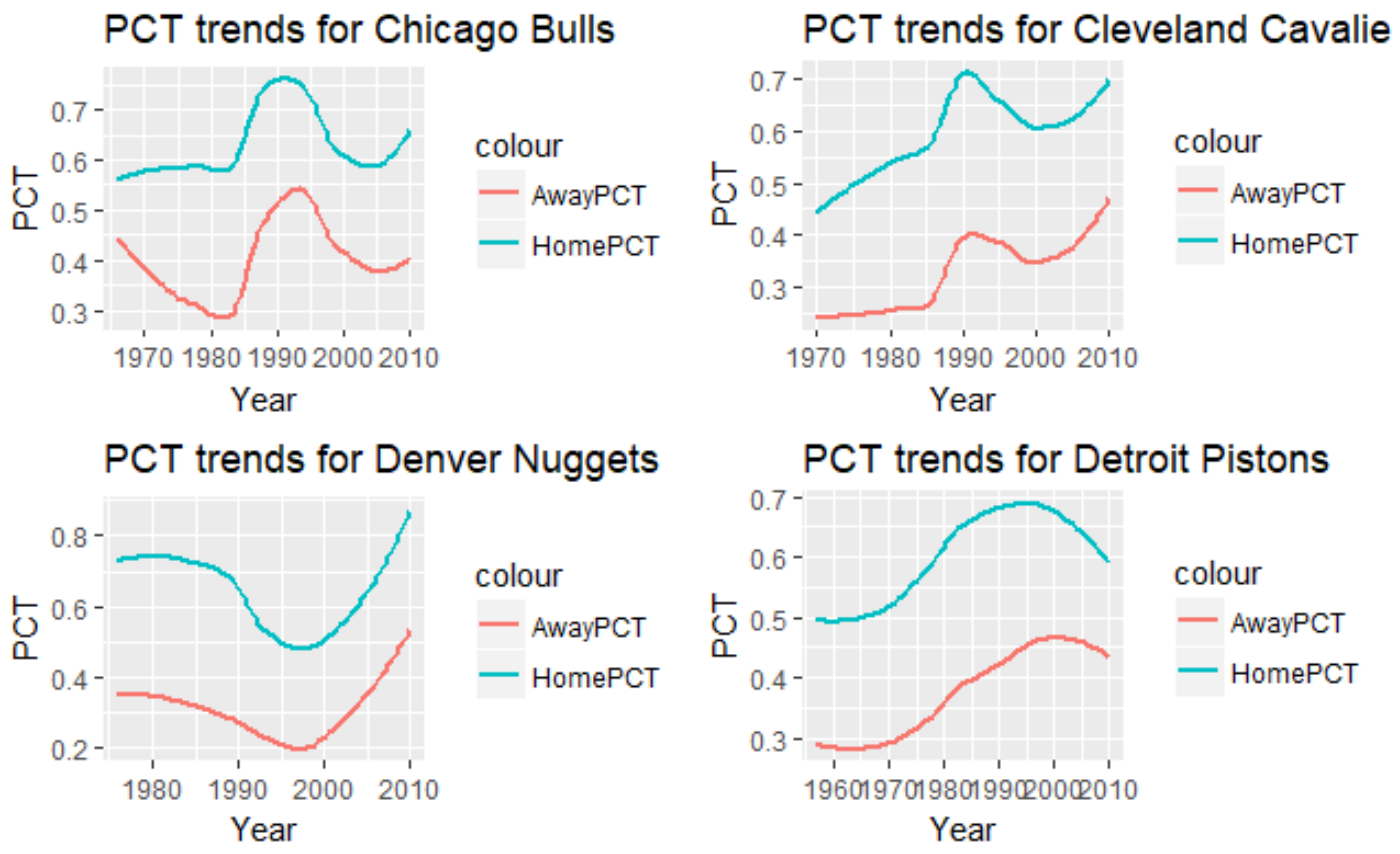

Figure 7. HomePCT and AwayPCT trends for teams 

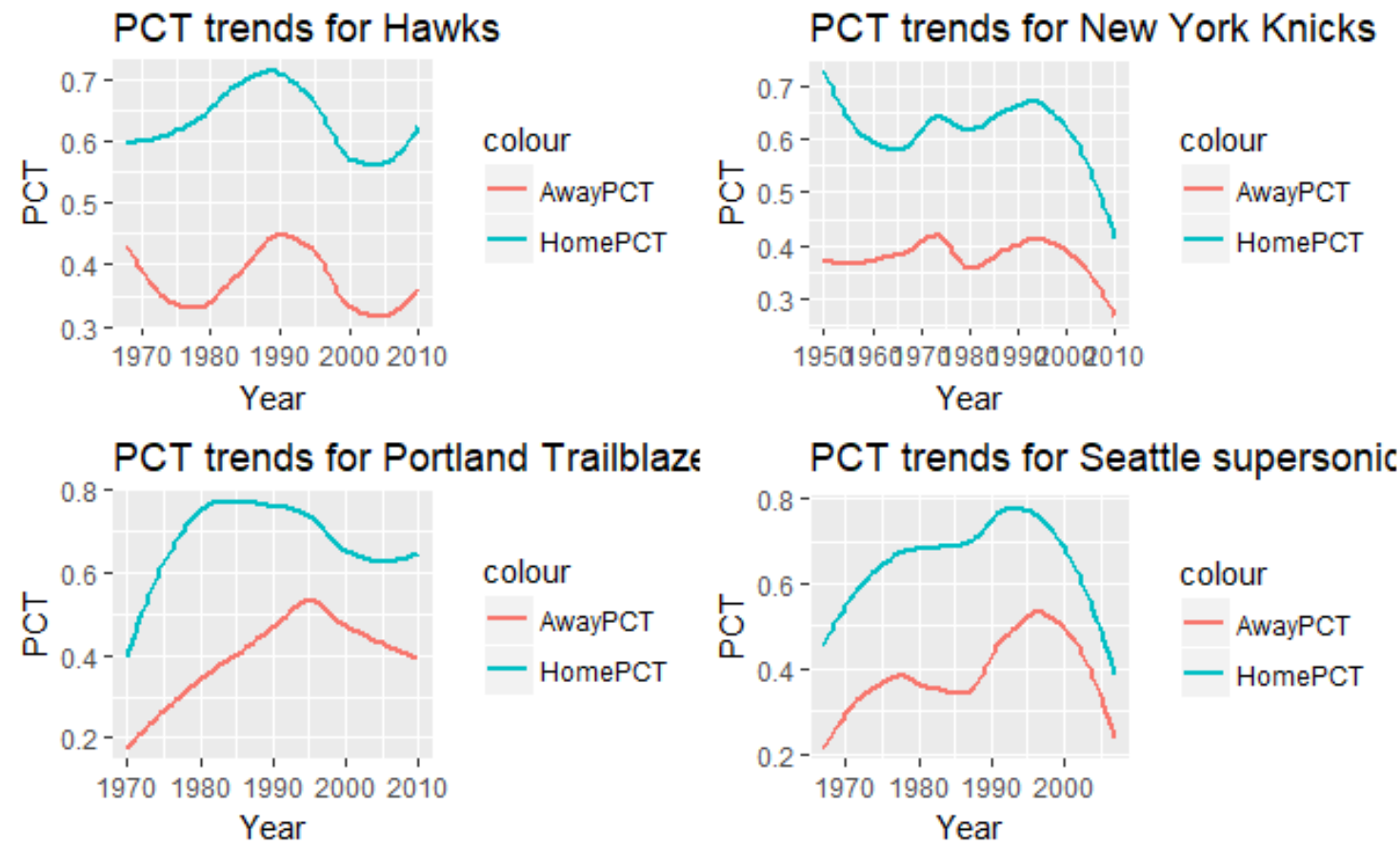

Figure 8. HomePCT and AwayPCT trends for teams

\section{CONCLUSION}

The aspect of group territoriality known as the Home Advantage undoubtedly exists in NBA. HomePCT and AwayPCT contribute as the most important variables for concluding our results. The infographs help in analyzing and visualizing the dataset and showcase that there is a decisive home advantage since teams have always performed better at home than at away games. Moreover, it supports the factors regarding psychological attributes that benefit the home team. We infer that team form is also important. A team in form is bound to give its best at both home and away games regardless of win or loss. For most teams it was observed that when the team had performed well at home games, the results reflected the same for away games; however, home advantage was still distinctively visible. In future, machine learning can be applied to infer in-depth knowledge of the factors attributing to home advantage in other sports.

\section{REFERENCES}

[1] Courneya KS, Carron AV. The home advantage in sport competitions: a literature review. J Sport Exerc Psychol 1992;14:13 -27.

[2] Snyder EE, Purdy DA. The home advantage in collegiate basketball. Soc Sport J 1985;2:352-6.

[3] Gayton WF, Coombs R. The home advantage in high school basketball. Percept Mot Skills 1995;82:1344- 6.

[4] Agnew JC, Carron AV. Crowd effects and the home advantage. Int J Sport Behav 1994;25:53-62.

[5] Mizruchi, M.S. Local sports teams and celebration of community: A comparative analysis of the home advantage. The Sociological Quarterly 1985;26:507-518.

[6] Ibanez, S. J., Sampaio, J., Feu, S., Lorenzo, A., Gómez, M. A., \& Ortega E. Basketball game-related statistics that discriminate between teams' season-long success. European Journal of Sport Science 2008;8:369-372.

[7] Silva, J. \& Andrew, J. An Analysis Of Game Location And Basketball Performance In The Atlantic Coast Conference. International Journal of Sport Psychology 1987;18:188-204. 
Computer Applications: An International Journal (CAIJ), Vol.8, No.3, August 2021

[8] Neave, N. \& Wolfson, S. Testosterone, territoriality and the 'home advantage'. Physiology and Behavior 2003;78:269-275.

[9] Nevill, A.M. \& Holder, R.L. Home advantage in sport: An overview of studies on the advantage of playing at home. Sports Medicine 1999;28:221-236.

[10] Pollard, R. Worldwide regional variations in home advantage in association football. Journal of Sports Sciences 2006;24:231-240.

[11] Pollard, R., \& Gómez, M. A. Home advantage analysis in different basketball leagues according to team ability. Iberian Congress on Basketball Research 2007;4:61-64.

[12] Pollard, R. Home advantage in football: a current review of an unsolved puzzle. The Open Sports Sciences Journal 2008;1:12- 14.

[13] Sampaio, J., Drinkwater, E., \& Leite, N. Effects of season period, team quality, and playing time on basketball players' game-related statistics. European Journal of Sport Science 2010;10:141-149.

[14] Silva, J. \& Andrew, J. An Analysis Of Game Location And Basketball Performance In The Atlantic Coast Conference. International Journal of Sport Psychology 1987;18:188-204.

[15] Varca, P. An Analysis Of The Home And Away Game Performance Of Male College Basketball Teams. Journal of Sport Psychology 1980;2:245-257.

[16] Baumeister, R.F. and Steinhilber. Paradoxical effects of supportive audiences on performance under pressure: the home field disadvantage in sports championships. Journal of Personality and Social Psychology 1984;47:85-93.

[17] Summer, J.and Mobley, M. Are cricket umpires biased? New Scientist 1981;29-31.

[18] Moskowitz, Tobias J., and L. Jon Wertheim, "What's Really Behind Home Field Advantage", Sports Illustrated, 2011; pp. 65-72.

[19] Balmer, N. J., Nevill, A. M., \& Williams, A. M. (2001). Home advantage in the Winter Olympics (1908-1998). Journal of Sports Sciences, 19, 129-139.

[20] Balmer, N. J., Nevill, A. M., \& Williams, A. M. (2003). Modelling home advantage in the Summer Olympic Games. Journal of Sports Sciences, 21, 469-478.

[21] Pollard, R., \& Pollard, G. (2005). Long-term trends in home advantage in professional team sports in North America and England (1876-2003). Journal of Sport Sciences, 23, 337-350.

[22] Carron, A. V., \& Eys, M. A. (2012). Group dynamics in sport (4th ed.). Morgantown, WV: Fitness Information Technology. 